\title{
DETECÇÃO DO GERENCIAMENTO DE RESULTADOS PELA ANÁLISE DO DIFERIMENTO TRIBUTÁRIO
}

\section{RESUMO}

O objetivo deste trabalho é verificar se a análise do diferimento tributário aumenta significativamente a detecção do gerenciamento de resultados nas companhias abertas brasileiras. Desenvolveu-se uma pesquisa empírica nos setores de mineração, siderurgia e metalurgia, e têxtil, durante o período de 2000 a 2004, utilizando-se as regressões probit e logit baseadas nos modelos Jones Modificado e Kang e Sivaramakrishnan (KS). Este estudo apresenta evidências de que a análise do diferimento tributário não aumenta o poder preditivo dos modelos analisados. Essa divergência pode ser explicada pelo fato de que a maioria dos trabalhos realizados foi direcionada ao contexto norte-americano, que supostamente apresenta diferentes fatores motivadores para o gerenciamento de resultados. Além disso, as diferenças das evidências empíricas no âmbito brasileiro podem ser originadas pelo uso da flexibilidade do método parcial de reconhecimento do diferimento dos tributos.

\section{Edílson Paulo}

Universidade Presbiteriana Mackenzie e FEA-USP

\section{Eliseu Martins}

FEA-USP

\section{Luiz João Corrar}

FEA-USP

\footnotetext{
ABSTRACT This article had as an objective to confirm if deferred tax income analysis increases significantly the detection of earnings management. Data were collected for the mining, steelworks, metallurgy and textile industries for the period 2000-2004, through probit and logit analysis established on the Modified Jones and Kang E Sivaramakrishnan models. The paper found evidences that analysis of deferred tax income does not increment the predictive power of the analyzed models. The divergence can be explained because most of the literature on the subject dealt with American firms and industries that supposedly have different incentive factors for earnings management. Further, the differences in Brazilian firms can be originated by the flexible use of the partial method for recognition of tax deferral.
}

PALAVRAS-CHAVE Gerenciamento de resultados, resultados contábeis, tributos diferidos, regressão probit, regressão logit. KEYWORDS Earnings management, accounting income, deferred tax, probit analysis, logit analysis. 


\section{INTRODUÇÃO}

A manipulação das informações contábeis tem sido objeto de diversos trabalhos na literatura internacional, em especial a norte-americana, que tem apresentado inúmeras pesquisas científicas. Entretanto, poucos pesquisadores realizaram estudos empíricos no contexto brasileiro (Martinez, 2001). A maior parte da literatura existente sobre gerenciamento de resultados apresenta, como principais evidências empíricas, a sua utilização para evitar resultados negativos ou para a manutenção de variabilidade dos resultados (Dechow, Sloan e Sweeney, 1995; Burgstahler e Dichev, 1997; Martinez, 2001; Fuji, 2004; Tukamoto, 2004). Entre outras razões para a prática de manipulação das informações contábeis, está aquela que os principais executivos da empresa [top managers] utilizam para benefícios próprios em prejuízo de outros.

Essa prática de manipulação traz prejuízos aos diversos usuários das informações contábeis, como investidores, que não possuem informações confiáveis para auxiliá-los na decisão de alocação de seus recursos; analistas financeiros, que apresentam previsões inseguras aos seus clientes; entidades regulamentadoras do mercado de capitais e da profissão contábil, que se vêem em situações incômodas e buscam novos instrumentos para evitar tais práticas; instituições de crédito e de financiamento, que não têm a verdadeira percepção sobre os riscos inseridos em suas negociações com as empresas que manipularam as informações contábeis; organismos governamentais, que regulamentam as atividades empresariais na economia global ou em setores específicos; entidades fazendárias, pois tal prática pode ser utilizada como uma forma de sonegação de arrecadação de tributos, além de dificultar a gestão fiscal por parte do governo; entidades sindicais, que não possuem informações confiáveis sobre a situação econômica e financeira da empresa para auxiliá-las nas negociações trabalhistas; e organizações não governamentais, que lutam contra a concentração de riqueza e abuso do poder econômico, principalmente contra aquelas empresas que trazem prejuízos sociais e ambientais.

As pesquisas empíricas nessa área têm tido como foco principal o gerenciamento do resultado contábil de cada exercício evidenciado na demonstração de resultados, pautadas em acumulações discricionárias agregadas. Uma alternativa para o uso das abordagens em acumulações agregadas seria a utilização de acumulações específicas ou em setores específicos, com o intuito de verificar quais itens são utilizados para o gerenciamento de resultados.

Alguns trabalhos fornecem evidências empíricas de que algumas contas contábeis revelam práticas de ge- renciamento de resultados (Burgstahler e Dichev, 1997). Seguindo a abordagem de acumulações específicas, Phillips, Pincus e Rego (2003) apresentam evidências de gerenciamento de resultados por meio do diferimento (ativo e passivo) de tributos, e os usuários das informações contábeis podem verificar tal prática analisando o diferimento tributário.

Diante disso, pode-se levantar o seguinte problema de pesquisa: A análise do diferimento dos tributos nas demonstrações contábeis das empresas brasileiras contribui, significativamente, para a melhoria dos estudos sobre práticas de gerenciamento de resultados?

O objetivo deste trabalho é verificar se a análise do diferimento do imposto de renda e contribuição social sobre o lucro líquido incrementa substancialmente a detecção do gerenciamento de resultados por parte das companhias abertas brasileiras. O estudo foi realizado nas companhias abertas brasileiras, nos setores de mineração, siderurgia e metalurgia, e têxtil, que possuam diferimento de tributos com base nas demonstrações contábeis findas entre os anos-calendário de 2000 a 2004.

Com o intuito de atingir o objetivo, realizou-se uma pesquisa exploratória que se destinou a buscar conhecimentos mais concretos, incorporando características não claramente explícitas, bem como procurando dimensões não conhecidas (Beuren, 2003, p. 81) e que necessitem ser mais bem compreendidas no ramo do conhecimento. Foi realizada uma pesquisa bibliográfica que procurou analisar e interpretar as contribuições científicas existentes sobre o tema, principalmente em livros, teses, dissertações e artigos, tanto nacionais quanto internacionais.

Utilizou-se também a abordagem empírica por meio da aplicação de alguns dos modelos econométricos descritos na literatura específica, para verificar se existe o aumento do poder preditivo na detecção de gerenciamento de resultados com a inclusão da análise do diferimento de tributos. As informações necessárias para a pesquisa foram obtidas dos bancos de dados da Comissão de Valores Mobiliários (CVM), Economática, e das próprias demonstrações contábeis publicadas, que compreenderam o exercício social de 1999 a 2004, devido à necessidade de algumas informações do ano anterior ao período que está sendo analisado.

\section{REFERENCIAL TEÓRICO E HIPÓTESES DE PESQUISA}

A manipulação das informações contábeis pode ser definida como a utilização de ações discricionárias por parte dos 
administradores para alterar a interpretação da realidade econômica e financeira da empresa. Segundo Stolowy e Breton (2004, p. 6), essa prática é motivada pelas possibilidades de transferências de riqueza entre a companhia e a sociedade (custos políticos), fontes de recursos (custo de capital) ou para os próprios administradores (planos de compensação); sendo que as duas primeiras situações tentam beneficiar a empresa, diferentemente do que ocorre na última situação.

A existência de critérios múltiplos nas normas e práticas contábeis possibilita aos administradores escolher alternativas válidas com o objetivo de apresentar informações da forma desejada, impactando o desempenho ou a estrutura financeira da empresa. Healy e Wahlen (1999, p. 368) consideram que gerenciamento de resultados ocorre quando os administradores usam julgamento discricionário para manipular as informações financeiras sobre o desempenho da companhia. Schipper (1989, p. 92) comenta que o gerenciamento de resultados é o processo de decisões deliberadas dentro dos limites impostos pelas normas contábeis, para apresentar o nível desejado de resultados.

Foram desenvolvidos alguns modelos para auxiliar o estudo sobre o gerenciamento de resultados por meio de análise das accruals [acumulações]. O termo "accruals" é apresentado como a diferença entre lucro líquido e fluxo de caixa operacional, que em verdade nada mais é do que a obediência ao regime de competência (accruals basis), que objetiva mensurar o resultado no sentido econômico, independentemente da realização financeira das transações e/ou eventos. Basicamente, a diferença entre accruals basis e cash basis é uma questão temporal (Martins, 1999) em termos globais, apesar de algumas divergências nas subclassificações, como no caso da imobilização, tratada no fluxo de caixa como atividade de investimento, e não atividade operacional, mas cujo reconhecimento no resultado, na forma de depreciação, por exemplo, é como despesa operacional.

Nas pesquisas sobre gerenciamento de resultados baseados em acumulações, existe a necessidade de separar as acumulações em:

- acumulações discricionárias [discretionary accruals]: são artificiais e teriam como objetivo somente manipular o resultado contábil; e

- acumulações não discricionárias [nondiscretionary accruals]: são inerentes às atividades da empresa.

A literatura contábil sobre o tema considera que as acumulações discricionárias seriam uma proxy do gerenciamento de resultados. Assim, baseando-se em acu- mulações agregadas ou acumulações especificas, foram desenvolvidos diversos modelos, apresentando-se as vantagens e desvantagens de cada proposta. A abordagem em acumulações específicas ou em setores específicos tem como objetivo principal verificar que itens contábeis estão sendo utilizados para o gerenciamento de resultados (Martinez, 2001, p. 45).

As pesquisas baseadas em acumulações estimam as total accruals por meio de modelos econométricos, objetivando decompô-las em fatores que reflitam as mudanças do ambiente econômico e financeiro da empresa. A detecção do gerenciamento de resultados dar-se-á com base nos resíduos do modelo, sendo estes considerados como proxy das abnormal (discretionary) accruals.

Apesar de se considerar, implicitamente, que as total accruals ponderadas pelos ativos totais se tornam constantes ao longo do tempo, observa-se que parte da variação no período analisado é esperada pela reversão das accruals de períodos anteriores (Dechow, 1994). Cabe ressaltar que nem toda accrual é evidência de prática de manipulação das informações contábeis, e que o que se avalia é a utilização anormal do montante de acumulações [abnormal accruals], controlando-se os demais fatores econômicos e financeiros.

Dentro da linha de acumulações específicas, algumas pesquisas (como Phillips, Pincus e Rego, 2003; Krull, 2004) avaliam a utilidade da análise do diferimento tributário como medida para detectar o gerenciamento de resultados, argumentando que as diferenças entre os registros contábeis e tributários auxiliam na separação entre as mudanças discricionárias e não discricionárias. Esses autores baseiam-se no argumento de que os critérios alternativos de mensuração dentro do sistema contábil permitem maiores montantes de acumulações discricionárias em cada período do que no tributário.

Como exemplo, a possibilidade de estimação a menor da despesa de provisão de perdas com recebimento de contas a receber melhora diretamente o resultado contábil do período, mas, segundo a legislação tributária atual, não gera reflexos nos cálculos de imposto de renda e contribuição social sobre o lucro líquido a pagar. Portanto, existem alguns critérios alternativos de reconhecimento de receitas e despesas que alteram as accruals, conseqüentemente influenciando os resultados contábeis, mas não possuem efeitos tributários.

As despesas (receitas) não dedutíveis (tributáveis), em um determinado período, são consideradas como ajustes permanentes ou temporários na base de cálculo do imposto de renda e/ou contribuição social. Os ajustes permanentes não apresentam reflexos tributários em 
períodos posteriores, portanto não existe a necessidade de reconhecimento da provável repercussão econômica e financeira em períodos posteriores ao reconhecimento de tal despesa ou receita.

Porém, os ajustes temporários apresentam reflexos tributários, quando do momento da permissão da dedutibilidade da despesa ou exigência da tributação de uma receita. Então, no período do reconhecimento de uma despesa (ou receita), deve-se avaliar a provável redução (ou aumento) do tributo nos períodos posteriores. Logo, buscando atender aos princípios contábeis da competência e da oportunidade, registra-se o direito gerado pelo pagamento a maior do tributo - baseado pela competência - como um ativo diferido; ou a obrigação pelo pagamento a menor como um passivo diferido. Portanto, os ajustes tributários temporários podem gerar ativos ou passivos tributários diferidos.

Assume-se, neste trabalho, que as empresas procuram gerenciar seus resultados contábeis, preferencialmente, sem aumentar seus desembolsos financeiros com tributos. Esse pressuposto é análogo ao assumir, a priori, que é menos oneroso para a empresa gerenciar os resultados por meio dos accruals do que pelo fluxo de caixa operacional. Portanto, as diferenças entre resultados contábeis e tributáveis geradas pelas accruals que não alteram o lucro tributável corrente auxiliam na separação das acumulações discricionárias e não discricionárias.

Alguns trabalhos empíricos (como Phillips, Pincus e Rego, 2003; Krull, 2004) apresentam evidências de que as empresas com incentivos de gerenciamento de resultados têm grandes diferenças entre os resultados contábeis e os tributáveis. Phillips, Pincus e Rego (2003, p. 492) argumentam que o erro mensurado nos modelos de total accruals usados para detectar gerenciamento de resultados pode ser reduzido pela observação da análise dos tributos diferidos, em vez da tentativa de decomposição das accruals em componentes normais e anormais.

Apesar dessa colocação, acabam efetuando a segmentação das accruals, fato esse que normalmente se apresenta nas pesquisas sobre o tema. Na realidade, é que a utilização de mais uma variável independente busca aumentar o poder preditivo do modelo proposto e, conseqüentemente, minimiza o erro da estimativa, mas nesse caso continuam-se decompondo as accruals.

Krull (2004, p. 67) confirma a utilidade do estudo das diferenças entre os resultados contábeis e tributários na detecção de gerenciamento de resultados e, seguindo a linha de pesquisa de Phillips et al. (2004), coloca que esses estudos podem ser melhorados por meio da investigação analítica dos componentes do passivo tri- butário diferido líquido (passivo tributário menos ativo tributário).

Diante do exposto, este trabalho busca identificar a utilidade da análise do diferimento de tributos para dois dos principais incentivos de gerenciamento de resultados: (1) evitar a divulgação de resultados negativos, e (2) reduzir a variabilidade dos resultados.

A divulgação de resultados negativos pode trazer efeitos indesejáveis, normalmente ligados à confiabilidade dos investidores, além de considerar que em muitas empresas as avaliações de desempenho dos administradores estão pautadas em números contábeis, inclusive a sua própria remuneração. Por isso, quando existe a possibilidade de gerenciar os resultados contábeis para que não se apresentem negativos nas demonstrações contábeis, os administradores das empresas sentem-se incentivados, agindo de forma discricionária. Então, a primeira hipótese testada neste trabalho pode ser descrita da seguinte forma:

$\mathrm{H}_{1}$ : A análise do diferimento do imposto de renda e da contribuição social sobre o lucro líquido aumenta significativamente a detecção de gerenciamento de resultados para evitar a divulgação de resultados negativos.

Segundo McKee (2005, p. 31), os analistas financeiros freqüentemente estimam a volatilidade dos resultados por meio dos desvios do lucro líquido contábil de períodos passados informados nas demonstrações contábeis. Uma maior volatilidade dos resultados passados afeta a capacidade de previsão dos resultados futuros, sugerindo um maior risco de investimento e, conseqüentemente, resulta em maiores prêmios ou taxas de desconto nos modelos de avaliação de empresas. Os administradores, quando incentivados por essa situação, efetuam essa prática de redução da variabilidade de resultados, conhecida como income smoothing. Então, testa-se a seguinte hipótese:

$\mathrm{H}_{2}$ : A análise do diferimento do imposto de renda e contribuição social sobre o lucro líquido aumenta significativamente a detectar o gerenciamento de resultados com o intuito de evitar a divulgação da variabilidade negativa dos resultados.

A literatura internacional apresenta outros incentivos para o gerenciamento de resultados, mas que não foram testados neste trabalho, ficando com dois dos incentivos que mais aparecem em trabalhos empíricos dessa natureza (Watts e Zimmerman, 1986; Jones, 1991; Roosenboom, Goot e Mertens, 2003). 


\section{DESENVOLVIMENTO DA PESQUISA E DO MODELO EMPÍRICO}

Para atender ao objetivo da pesquisa, foram analisadas as demonstrações contábeis de 59 companhias abertas listadas na Bolsa de Valores de São Paulo (Bovespa), nos setores de mineração, siderurgia e metalurgia, e têxtil durante o período de 2000 a 2004. No total foram 295 empresasano. Os dados necessários foram coletados do banco de dados da Comissão de Valores Mobiliários (CVM) e da Economática, e das demonstrações contábeis publicadas pelas próprias empresas.

Em trabalhos empíricos na área de contabilidade e finanças é muito comum a utilização de modelos de regressão, em que as variáveis independentes sejam representadas por variáveis dummies. Entretanto, em algumas situações peculiares, as variáveis dependentes também são tratadas dessa forma. Nesse caso, as variáveis dependentes analisadas não são contínuas, podendo assumir valor binário (chamadas de variáveis dicotômicas) ou mais de duas respostas (variáveis multicotômicas), mas sempre representadas por valores discretos.

Gujarati (2000) coloca que as abordagens mais comuns em aplicações de modelos dessa natureza são: modelo de probabilidade linear (MPL), modelo probit, modelo logit (normit) e modelo tobit. Os modelos probit e logit assumem que a variável dependente tem caráter binário representado pelos valores 1 e 0 . Os referidos modelos mensuram a relação entre a força dos estímulos e a proporção de casos observados a uma determinada resposta aos estímulos, ou seja, observam o impacto das variáveis explicativas na probabilidade de decidir com base em um determinado estímulo (incentivo). Os modelos de estimação de regressão a serem utilizados neste estudo serão o probit e o logit, que se baseiam, respectivamente, nas funções de distribuição normal cumulativa e distribuição normal logística, a qual possibilita uma transformação no modelo, garantindo que, para qualquer $\mathrm{x}$, as estimativas de probabilidade estejam no intervalo entre 0 e 1 . O autor ainda destaca que a escolha da utilização do modelo probit ou logit é uma questão de conveniência matemática e de disponibilidade de recursos computacionais, pois existe somente uma ligeira diferença entre as caudas das curvas de distribuição acumuladas.

O MPL não é recomendável quando a variável dependente é dicotômica, que pode ser representada por 0 ou 1 (por exemplo, falso e verdadeiro), pois os valores estimados podem assumir números negativos ou maiores que 1 , além de, normalmente, existirem pro- blemas de heteroscedasticidade e não normalidade dos erros. Outro problema nesse modelo é a existência da suposição de que a probabilidade aumenta ou diminui linearmente com a variável estatística, ou seja, o efeito marginal é constante na função. O modelo tobit é mais recomendado quando em uma amostra as informações sobre o regressando estejam disponíveis somente para algumas observações, conhecida como amostra censurada (Gujarati, 2000).

Na maioria dos trabalhos empíricos sobre esse tema são utilizados os modelos Jones Modificado (Dechow, Sloan e Sweeny, 1995) e KS (Kang e Sivaramakrishnan, 1995) para detectar evidências de gerenciamento de resultados, sendo que o primeiro apresenta-se com maior freqüência na literatura internacional (Dechow, Sloan e Sweeney, 1995; Burgstahler e Dichev, 1997; Teoh, Welch e Wong, 1998; Healy e Wahlen, 1999; Bartov, Givoly e Hayn, 2002; Roosenboom, Goot e Mertens, 2003; Bartov e Mohanram, 2004), enquanto o segundo tem apresentado melhores resultados no contexto brasileiro (Martinez, 2001). Assim, para se obter maior robustez e confiabilidade nos resultados desta pesquisa, são utilizados esses dois modelos, brevemente expostos a seguir.

O objetivo da inclusão de uma variável representativa do diferimento tributário é aumentar o poder preditivo da estimação dos modelos de detecção de gerenciamento de resultados analisados neste trabalho. Como exposto anteriormente, a utilização dessa variável está baseada no pressuposto de que as escolhas de mensuração (julgamentos) no sistema contábil permitem um maior volume de acumulações discricionárias em cada período do que no sistema tributário. Assim, o diferimento tributário originado pelas diferenças entre os resultados contábil e tributário auxiliaria na identificação entre as mudanças discricionárias e não discricionárias.

Para investigar o gerenciamento de resultados com base na primeira hipótese, de evitar a divulgação de resultados negativos, utilizou-se o seguinte modelo de regressão:

$E M_{i t}=\alpha+\beta_{1} D T D_{i t}+\beta_{2} A C_{i t}+\beta_{3} F C O_{i t}+\varepsilon_{i t}$

em que:

$E M_{i t}=$ empresa com incentivos para gerenciar resultados, 1 se o resultado líquido da empresa $i$ do ano $t$ dividido pelo seu ativo total no fim do ano $t-1$ for $\geq 0$ e $<0,1$; e 0 se o resultado líquido estiver entre $\geq-0,1$ $\mathrm{e}<0$;

$D T D_{i t}=$ diferença líquida entre o montante de despesa e receita tributária diferida da empresa $i$ no ano $t$, ponderada pelo ativo total do final do ano $t-1$; 
$A C_{i t}=$ acumulações discricionárias da empresa $i$ no ano $t$;

$\mathrm{FCO}_{i t}=$ fluxo de caixa das atividades operacionais da empresa $i$ do ano $t$, ponderado pelo ativo total do final do ano $t-1$;

$\varepsilon_{i t}=$ erro;

$\alpha e \beta_{i}=$ coeficientes linear e angulares do modelo.

Seguindo os modelos propostos por Burgsstahler e Dichev (1997) e Phillips, Pincus e Rego (2003), EM $M_{t i}$ será igual a 1 se a empresa $i$ informar resultados contábeis ponderados pelo ativo total, no ano $t$ dentro do intervalo $[0 ; 0,1]$; ou igual a 0 se a variação estiver no intervalo $[-0,1 ; 0]$. Esses modelos propostos partem da suposição de que as empresas teriam incentivos para gerenciar resultados a fim de evitar a divulgação de resultados negativos pequenos, alterando para que fossem apresentadas melhorias nos seus desempenhos, conforme a Figura 1.

O coeficiente positivo e significativo da variável $D T D_{i t}$ na Equação 1 indica que a probabilidade de gerenciamento de resultados para evitar a divulgação de resultados negativos é incrementada com o diferimento dos tributos.

A inclusão da variável $\mathrm{FCO}_{i t}$ tem como objetivo controlar o efeito do fluxo de caixa operacional no status de gerenciamento por parte da empresa, considerando que um aumento no fluxo de caixa operacional, normalmente, reflete uma melhora nos lucros, reduzindo, assim, a necessidade de gerenciamento de resultados para eliminar nos lucros negativos correntes. A variável $F C O_{i t}$ foi obtida por meio do item caixa líquido nas atividades operacionais contidas na demonstração do fluxo de caixa (DFC), ou, quando não divulgada, foi calculada por meio da demonstração de origens e aplicações de recursos, com base no item total dos recursos provenientes das operações e ajustada pelos itens utilizados pelo método indireto para elaborar a DFC.

A variável $A C_{i t}$ representa um dos modelos para cálculo das acumulações discricionárias existentes na literatura atual. A utilização das variáveis $A C_{i t}$ e $D T D_{i t}$ nos modelos é justificada para verificar a utilidade da análise do diferimento de tributos no gerenciamento de resultados (Phillips, Pincus e Rego, 2003).

É necessário que, no modelo descrito pela Equação 1, no caso de gerenciamento de resultados para evitar a variabilidade dos resultados contábeis (segunda hipótese), se inclua a variável que representa a variação do fluxo de caixa das atividades operacionais no período corrente e o do período anterior, no lugar do montante do fluxo de caixa do período. Assim, a variável dependente dicotômica passa a descrever o status da variabilidade dos resultados. Obtém-se, assim, a seguinte função:

$E M_{i t}=\alpha+\beta_{1} D T D_{i t}+\beta_{2} A C_{i t}+\beta_{3} \Delta F C O_{i t}+\varepsilon_{i t}$

em que:

$E M_{i t}=$ empresa com incentivos para gerenciar resultados, 1 se a variação no lucro líquido da empresa $i$ do ano $t-1$ para $t$ dividido pelo seu ativo total no fim do ano $t-1$ for $\geq 0$ e $<0,1$; e 0 se a variação no lucro líquido estiver entre $\geq-0,1$ e $<0$;

Figura 1 - Gerenciamento de resultados negativos

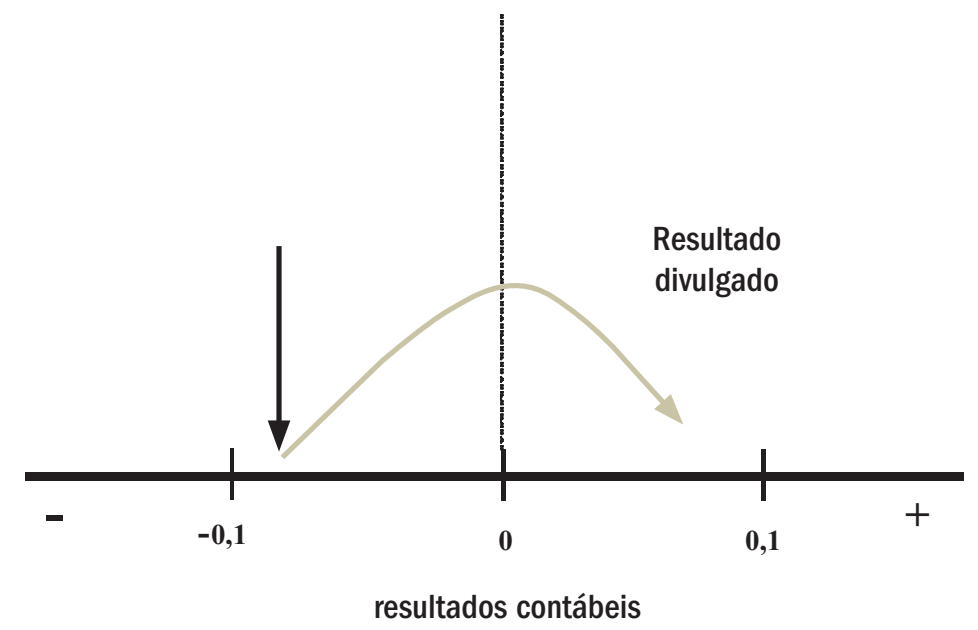


$\Delta \mathrm{FCO}_{i t}=$ variação do fluxo de caixa das atividades operacionais da empresa $i$ do ano $t-1$ para o ano $t$, ponderada pelo ativo total do final do ano $t$ - 1 .

Essa alteração no modelo para a segunda hipótese tem como objetivo controlar o efeito da variação do fluxo de caixa operacional no status de gerenciamento por parte da empresa, considerando que uma variação no fluxo de caixa operacional reflete diretamente na variabilidade dos lucros correntes. Assim, os modelos propostos neste artigo seguem os preconizados por trabalhos anteriores (Burgstahler e Dichev, 1997; Phillips, Pincus e Rego, 2003).

Para testar a utilidade incremental da análise do diferimento dos tributos foram utilizados os modelos mais comuns para detectar gerenciamento de resultados para o calculo da variável $A C_{i t}$ : o Jones Modificado (Dechow, Sloan e Sweeney, 1995) e o Modelo KS (Kang e Sivaramakrishnan, 1995). O primeiro modelo foi testado nos trabalhos de Phillips, Pincus e Rego (2003), Phillips et al. (2004) e Krull (2004); enquanto o segundo foi utilizado na tese de Martinez (2001) para estimar as acumulações discricionárias nas companhias abertas brasileiras.

O modelo Jones Modificado (Dechow, Sloan e Sweeney, 1995) pode ser descrito da seguinte maneira:

$$
J M T A C c_{i t}=\alpha+\beta_{1}\left(\Delta R_{i t}-\Delta C R_{i t}\right)+\beta_{2} A I_{i t}+\varepsilon_{1}
$$

em que:

JMTACc $_{i t}=$ total accruals no ano $t$ por meio do modelo Jones Modificado;

$\Delta R_{i t}=$ variação das receitas líquidas da empresa $i$ do $t$ - 1 para o ano $t$;

$\Delta C R_{i t}=$ variação da conta duplicatas a receber (clientes) da empresa $i$ do $t$ - 1 para o ano $t$;

$A I_{i t}=$ saldo da conta ativo imobilizado e ativo diferido da empresa $i$ no ano $t$;

$\varepsilon_{i t}=$ erro.

As variáveis $\Delta R_{i t}, \Delta C R_{i t}$ e $I_{i t}$ são ponderadas pelos ativos totais no início do período, enquanto $\alpha$ é a constante, $\beta_{1}$ e $\beta_{2}$ são os coeficientes das variáveis preditoras. Já no modelo KS (Kang e Sivaramakrishnan, 1995), as accruals são estimadas por meio da seguinte regressão:

$\operatorname{KSTACc}_{i t}=\phi_{0}+\phi_{1}\left(\delta_{1} R_{i t}\right)+\phi_{2}\left(\delta_{2} D_{i t}\right)+\phi_{3}\left(\delta_{3} A I_{i t}\right)+\varepsilon_{i t}$

em que:

$\mathrm{KSTACc}_{i t}=$ total accruals da empresa $i$ no ano $t$ por meio do modelo KS;

$R_{i t}=$ montante das receitas líquidas da empresa $i$ no ano $t$;

$D_{i t}=$ montante dos custos e despesas operacionais no ano $t$, excluídas as despesas com depreciação e amortização;

$A I_{i t}=$ saldo da conta ativo imobilizado e ativo diferido da empresa $i$ no ano $t$;

$\Delta C G L_{i t}=$ variação do capital de giro líquido no final do ano $t-1$ para o ano $t$, excluindo-se as disponibilidades e financiamento de curto prazo;

$C R_{i t}=$ montante da conta duplicatas a receber (clientes) da empresa $i$ no ano $t$;

Depr $_{i t}=$ montante das despesas com depreciação e amortização no ano $t$;

$\delta_{1}=C R_{i, t-1} / R_{i, t-1}$;

$\delta_{2}=\left(\Delta C G L_{i t}-C R_{i t}\right) / D_{i, t-1}$;

$\delta_{3}=\operatorname{Depr}_{i, t-1} / A I_{i, t-1}$;

$\varepsilon_{i t}=$ erro.

Todas as variáveis do modelo KS são ponderadas pelos ativos totais no início do período, enquanto $\Phi 0$ é a constante e $\Phi 1, \Phi 2$ e $\Phi 3$ são os coeficientes das variáveis preditoras.

\section{ANÁLISE DOS RESULTADOS}

Inicialmente realizou-se uma análise descritiva do conjunto de observações. Do total de 295 empresas-ano, 287 observações apresentaram dados disponíveis para análise do comportamento da variabilidade dos resultados contábeis durante o período analisado, sendo que parte da perda desses dados deve-se à falta de divulgação das demonstrações contábeis pelas empresas. Somente em 143 dessas empresas-ano foi observada a evidenciação de diferimento de tributos, representando $48 \%$ do total das observações colhidas. Os dados da estatística descritiva e o teste de normalidade encontram-se nas Tabelas 1 e 2.

Com o intuito de verificar a normalidade das variáveis neste trabalho foi utilizado o Teste K-S (KolmogorovSmirnov), no qual demonstra que não existem evidências estatísticas para rejeitar a normalidade dos resultados no período, ou seja, a variável resultado no período t ponderado pelo ativo total em $t$ - 1 segue uma distribuição normal. Enquanto a variabilidade do resultado em $t$ ponderado pelo ativo total em $t$-1, não apresenta normalidade amostral. Em ambos os casos se consideraram um nível de significância de 0,05. 
Tabela 1 - Estatística descritiva

\begin{tabular}{|l|c|c|c|c|c|}
\hline & N & MÉDIA & DESVIO PADRÃO & MÍNIMO & MÁXIMO \\
\hline Resultado no período & 143 & 0,0644 & 0,0994 & $-0,2797$ \\
\hline Variabilidade dos resultados & 143 & 0,0330 & 0,1021 & $-0,3375$ \\
\hline
\end{tabular}

Tabela 2 - Teste Kolmogorov-Smirnov

\begin{tabular}{|c|c|c|c|}
\hline & & RESULTADO NO PERÍODO & $\begin{array}{l}\text { VARIABILIDADE DOS } \\
\text { RESULTADOS }\end{array}$ \\
\hline \multirow[t]{3}{*}{ Most extreme differences } & Absolute & 0,097 & 0,116 \\
\hline & Positive & 0,097 & 0,116 \\
\hline & Negative & $-0,059$ & $-0,091$ \\
\hline \multicolumn{2}{|l|}{ Kolmogorov-Smirnov Z } & 1,162 & 1,391 \\
\hline \multicolumn{2}{|l|}{ Asymp. Sig. (2-tailed) } & 0,134 & 0,042 \\
\hline
\end{tabular}

Figura 2 - Histograma dos resultados contábeis escalonados pelos ativos totais

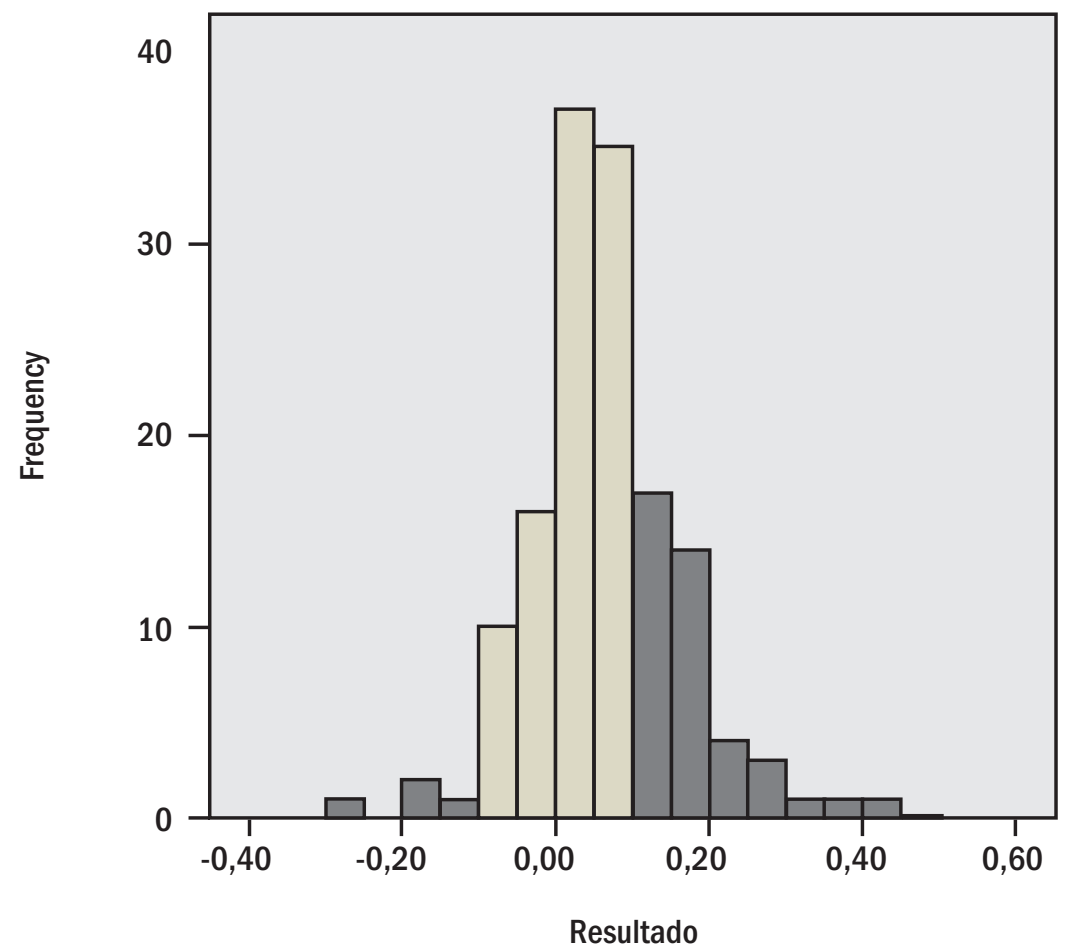


Conforme a Figura 2, na análise do comportamento do lucro líquido do ano $t$ ponderado pelo ativo total do ano $t-1$, observam-se comportamentos anormais em torno do resultado nulo dos resultados (ponto de referência). Essa constatação por meio da análise do histograma apresenta evidências de gerenciamento de resultados para evitar a divulgação de perdas contábeis. Para atender aos objetivos desta pesquisa foram consideradas somente as observações classificadas em 0 e 1 para a variável EMit na primeira hipótese, respectivamente, 25 e 70 empresas-ano.

O histograma da Figura 3 também apresenta comportamentos anormais em torno da variabilidade zero dos resultados no período corrente em relação ao anterior, apresentando, portanto, evidências de gerenciamento de resultados para evitar a variabilidade de resultados. Assim, deve-se realizar uma análise mais aprofundada das duas hipóteses mediante os modelos econométricos propostos neste estudo. Conforme estabelecido na segunda hipótese, somente foram consideradas as observações classificadas em 0 e 1 para a variável $E M_{i t}$, respectivamente, 41 e 66 empresas-ano.

Nas Tabelas 3 e 4, respectivamente, relatam-se os re- sultados dos modelos de Jones Modificado e KS (Kang e Sivaramakrishnan), para as regressões probit e logit na hipótese de gerenciamento de resultados com o intuito de evitar a divulgação de resultados negativos durante o período corrente. Com base nos dados apresentados aplicados às regressões probit e logit, utilizando os dois modelos, somente a $D T D_{i t}$ não é estatisticamente significativa na detecção de gerenciamento de resultados, negando a primeira hipótese levantada neste trabalho, considerando-se um nível de significância de 0,05.

A interpretação dos coeficientes das variáveis torna-se complicada pelo fato de não representar efeito marginal na variável dependente (QMS, 1998), sendo que valores positivos nos coeficientes $(\beta i)$ implicam que um incremento na variável independente (co-variada) aumentará a probabilidade de resposta afirmativa (representada pelo valor 1 na variável binária). Com base nos dados estimados pelo modelo KS, um aumento na variável $D T D_{i t}$ reduz a probabilidade de gerenciamento de resultados, o que não confirma a hipótese levantada. Cabe observar que, as regressões calculadas sobre o modelo KS apresentam melhor valor preditivo do que os estimados pelo modelo Abnormal Accruals.

Figura 3 - Histograma da variabilidade dos resultados contábeis ponderados pelos ativos totais

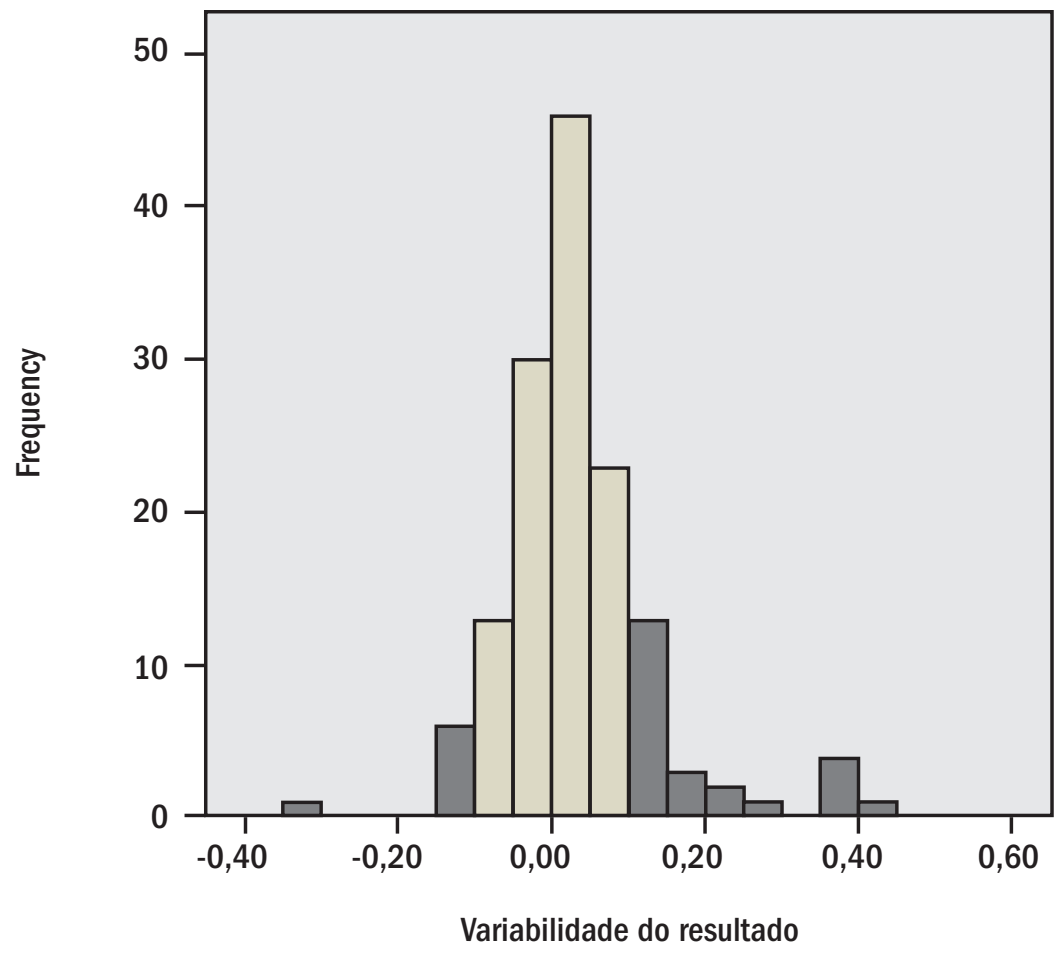


A estatística LR (LR statistic) testa a hipótese nula, de que todos os coeficientes das variáveis independentes na regressão binária são iguais a zero, testando a significância geral do modelo; enquanto McFadden $R^{2}$ indica quanto da variação de probabilidade da variável dependente é explicado pelas variáveis independentes do modelo.

Em todos os modelos de regressão analisados na primeira hipótese deste trabalho, o LR statistic mostra que pelo menos uma das variáveis é significativa para explicar a $E M_{i t}$. Na hipótese de gerenciamento de resultados para evitar a divulgação de resultados negativos (H1), as estatísticas baseadas no modelo Jones Modificado apresentam baixo poder explicativo (McFadden $R^{2}$ para probit e logit, respectivamente, 0,1832 e 0,1828 ), havendo um melhora na predição quando aplicado o modelo $\mathrm{KS}$, mas observa-se que a variável (de interesse) DTD não é estatisticamente significativa em todos os modelos ( $p$-value $>0,05)$. As regressões calculadas sob o modelo $\mathrm{KS}$ apresentam melhor valor preditivo do que as estima- das pelo modelo abnormal accruals, o que é comprovado, também, pelos critérios Akaike e Schwarz (ou seja, quanto menor o coeficiente desses testes, melhor o valor preditivo do modelo).

Analisando a segunda hipótese deste trabalho, as Tabelas 5 e 6 apresentam os resultados baseados nos modelos Jones Modificado e KS, respectivamente, para as regressões probit e logit, na qual demonstram que os coeficientes da variável $D T D_{i t}$ não são significativamente diferentes de 0 , o que leva a concluir que em nenhum dos modelos propostos a inclusão da variável despesa tributária diferida apresenta uma contribuição para detectar o gerenciamento de resultados com o intuito de evitar a variabilidade dos lucros. No caso de gerenciamento com o intuito de evitar variabilidade negativa dos resultados por meio do modelo KS, mostra que pelo menos uma das variáveis é significativa, a variável $\triangle F C O_{i t}$, mas, nesse modelo, novamente demonstra-se que ela não é estatisticamente significativa.

Em todos os modelos testados nas duas hipóteses anali-

Tabela 3 - Gerenciamento de resultados para evitar divulgação de perdas contábeis: Modelo Jones Modificado

\begin{tabular}{|l|c|c|c|c|}
\hline \multirow{2}{*}{} & \multicolumn{2}{|c|}{ PROBIT } & \multicolumn{2}{c|}{ LOGIT } \\
\cline { 2 - 5 } & COEFFICIENT & P-VALUE & COEFFICIENT & P-VALUE \\
\hline Interceptor & 0,6449 & 0,00 & 1,0671 & 0,00 \\
\hline DTD $_{i t}$ & 8,1297 & 0,09 & 14,1770 & 0,10 \\
\hline FCO $_{i t}$ & $1,83 \mathrm{E}-06$ & 0,05 & $3,31 \mathrm{E}-06$ & 0,04 \\
\hline AbAcc $_{i t}$ & 16,9766 & 0,00 & 28,8561 & 0,00 \\
\hline & & & & 0,00 \\
\hline LR Statistic & 20,0577 & 0,00 & 20,0212 & \\
\hline McFadden $R^{2}$ & 0,1832 & & 0,1828 & \\
\hline Akaike criterion & 1,0257 & & 1,0261 & \\
\hline Schwarz criterion & 1,1333 & & 1,1336 & \\
\hline$n$ & 95 & & 95 & \\
\hline
\end{tabular}

Modelo empregado para investigar o gerenciamento de resultados na hipótese de evitar a divulgação de resultados negativos (equação 1): $E M_{i t}=\alpha+\beta_{1} D T D_{i t}+\beta_{2} A C_{i t}+\beta_{3} F C O_{i t}$ $E M_{i t}=$ empresa com incentivos para gerenciar resultados, 1 se o resultado líquido da empresa $i$ do ano $t$ dividido pelo seu ativo total no fim do ano $t-1$ for $\geq 0$ e $<0,1$; e 0 se o resultado líquido estiver entre $\geq-0,1$ e $<0$;

$D T D_{i t}=$ diferença líquida entre o montante de despesa e receita tributária diferida da empresa $i$ no ano $t$

$\mathrm{FCO}_{i t}=$ fluxo de caixa das atividades operacionais da empresa $i$ no ano $t$;

$A C_{i t}=$ acumulações discricionárias da empresa $i$ no ano $t$, calculado pelo modelo Jones Modificado $J M T A c c_{i t}(\underline{\text { equação } 3})$ :

$A C_{i t}=J M T A C C_{i t}=\alpha+\beta_{1}\left(\Delta R_{i t}-\Delta C R_{i t}\right)+\beta_{2} A l_{i t}$

$\Delta R_{i t}=$ variação das receitas líquidas da empresa $i$ do $t$-1 para o ano $t$;

$\Delta C R_{i t}=$ variação da conta duplicatas a receber (clientes) da empresa $i$ do $t-1$ para o ano $t$;

$A l_{i t}=$ saldo da conta ativo imobilizado e ativo diferido da empresa i no ano $t$;

Todas as variáveis ponderadas pelo ativo total no final do ano $t-1$. 
sadas neste trabalho, evidencia-se que a inclusão da análise dos tributos diferidos nos modelos Jones Modificado e KS para detectar gerenciamento de resultados não apresenta aumento no poder preditivo. Complementarmente, observa-se que a regressão probit ou logit apresenta resultados significativamente semelhantes, o que condiz com o que foi colocado anteriormente.

\section{CONSIDERAÇÕES FINAIS}

A pesquisa empírica sobre o gerenciamento de resultados no Brasil pode ser considerada incipiente em relação a outros centros de pesquisas, não apenas pela falta de banco de dados completos e consistentes, mas principalmente pela ausência de uma melhor divulgação por parte das companhias abertas nacionais. Isso se agrava quando se procura realizar tais pesquisas sobre as companhias fechadas e demais tipos de sociedade.

Apesar da existência de pesquisas empíricas internacionais no sentido de que a inclusão da análise do diferimento dos tributos contribui positivamente para uma melhoria na detecção de gerenciamento de resultados em seus diversos incentivos, este artigo apresentou evi-

Tabela 4 - Gerenciamento de resultados para evitar divulgação de perdas contábeis: modelo Total Accruals KS

\begin{tabular}{|l|c|c|c|c|}
\hline & \multicolumn{3}{|c|}{ PROBIT } & \multicolumn{2}{c|}{ LOGIT } \\
\cline { 2 - 5 } & COEFFICIENT & P-VALUE & COEFFICIENT & P-VALUE \\
\hline Interceptor & 2,8571 & 0,01 & 5,5563 & 0,02 \\
\hline DTD $_{i t}$ & $-0,5990$ & 0,91 & $-2,0640$ & 0,85 \\
\hline FCO $_{i t}$ & $2,16 \mathrm{E}-05$ & 0,03 & $4,07 \mathrm{E}-05$ & 0,04 \\
\hline KSTacc $_{i t}$ & 179,2990 & 0,03 & 359,0835 & 0,05 \\
\hline & & & & 0,00 \\
\hline LR Statistic & 27,6520 & 0,00 & 28,0270 & \\
\hline McFadden $R^{2}$ & 0,4213 & & 0,4270 & \\
\hline Akaike criterion & 0,8515 & & 0,8445 & \\
\hline Schwarz criterion & 0,9987 & & 0,9918 & \\
\hline$n$ & 95 & & 95 & \\
\hline
\end{tabular}

Modelo empregado para investigar o gerenciamento de resultados na hipótese de evitar a divulgação de resultados negativos (equação 1): $E M_{i t}=\alpha+\beta_{1} D T D_{i t}+\beta_{2} A C_{i t}+\beta_{3} F C O_{i t}$

$E M_{i t}=$ empresa com incentivos para gerenciar resultados, 1 se o resultado líquido da empresa $i$ do ano $t$ dividido pelo seu ativo total no fim do ano $t$ - 1 for $\geq 0$ e $<0,1$; e 0 se o resultado líquido estiver entre $\geq-0,1$ e $<0$;

$D T D_{i t}=$ diferença líquida entre o montante de despesa e receita tributária diferida da empresa $i$ no ano $t$;

$\mathrm{FCO}_{i t}=$ fluxo de caixa das atividades operacionais da empresa $i$ do ano $t$-1 para o ano $t$;

$A C_{i t}=$ acumulações discricionárias da empresa $i$ no ano $t$, utilizando o total accruals no ano $t$ calculado pelo modelo Jones Modificado

$K S T A C C_{i t}$ (equação 4) $: A C_{i t}=K S T A C c_{i t}==\Phi_{0}+\Phi_{1}\left(\delta_{1} R_{i t}\right)+\Phi_{2}\left(\delta_{2} D_{i t}\right)+\Phi_{3}\left(\delta_{3} A l_{i t}\right)$

$K S T A C C_{i t}=$ total accruals da empresa $i$ no ano $t$ pelo modelo $\mathrm{KS}$;

$R_{i t}=$ montante das receitas líquidas da empresa $i$ no ano $t$;

$D_{i t}=$ montante dos custos e despesas operacionais da empresa $i$ no ano $t$, excluídas as despesas com depreciação e amortização;

$A I_{i t}=$ saldo da conta ativo imobilizado e ativo diferido da empresa i no ano $t$;

$\Delta C G L_{i t}=$ variação do capital de giro líquido da empresa $i$ no final do ano $t$-1 para o ano $t$, excluindo-se as disponibilidades e financiamen-

to de curto prazo;

$C R_{i t}=$ montante da conta duplicatas a receber (clientes) da empresa $i$ do ano $t-1$ para o ano $t$;

$\operatorname{Depr}_{i t}=$ montante das despesas com depreciação e amortização da empresa $i$ do ano $t$;

$\delta_{1}=C R_{i, t-1} / R_{i, t-1}$;

$\delta_{2}=\left(\Delta C G L_{i t}-C R_{i t}\right) / D_{i, t-1}$;

$\delta_{3}=\operatorname{Depr}_{i, t-1} / A I_{i, t-1}$.

Todas as variáveis ponderadas pelo ativo total no final do ano $t-1$. 
dências de que o mesmo fato não pode ser comprovado na análise efetuada sobre os setores e o período especificados neste trabalho. Mas é importante lembrar que a maioria desses trabalhos realizados até então foram voltados ao contexto norte-americano, que, supostamente, apresenta fatores motivadores para o gerenciamento de resultados diferentes dos estímulos nacionais. Além disso, deve-se considerar que outros trabalhos não encontram evidências nesse mesmo mercado acionário (Miller e Skinner, 1998).

Essa divergência também pode ser explicada pelo uso da flexibilidade propiciada pelo método parcial do diferimento dos tributos, o que conduziria a uma mensuração oportunista por meio do seu não reconhecimento, sendo evidenciado em notas explicativas [off balance sheet]. Um exemplo desse fato seria o não reconhecimento do ativo tributário diferido ocasionado pelos prejuízos fiscais que não apresentariam possibilidade de recuperação econômica em períodos subseqüentes, o que, de forma geral, prejudica a utilidade da análise dos tributos diferidos. Cabe ressaltar que a possibilidade de realização da receita é uma condição essencial para seu reconhecimento contábil. Assim, o não reconhecimento do ativo tributário diferido, quando inexiste a expectativa de recuperação econômica, encontra-se coerente com a teoria contábil.

As evidências apresentadas limitam-se à amostra deste trabalho, bem como a questões metodológicas na utilização dos modelos Jones Modificado e KS (Kang e Sivaramakrishnan) para a detecção de gerenciamento de resultados. Seguindo a linha de outras pesquisas (Phillips et al., 2004; Krull, 2004; Gordon e Joss, 2004), torna-se interessante buscar outras metodologias de pesquisas para detectar empiricamente o gerenciamento de resultados, por meio da análise dos componentes do diferimento tributário, que podem apresentar resultados mais consistentes com a fundamentação teórica e a realidade brasileira.

Tabela 5 - Gerenciamento de resultados para evitar variabilidade dos resultados contábeis: modelo Jones Modificado

\begin{tabular}{|c|c|c|c|c|}
\hline & \multicolumn{2}{|c|}{ PROBIT } & \multicolumn{2}{|c|}{ LOGIT } \\
\hline & COEFFICIENT & P-VALUE & COEFFICIENT & P-VALUE \\
\hline Interceptor & 0,2029 & 0,13 & 0,3102 & 0,17 \\
\hline$D_{i t}$ & $-1,5276$ & 0,48 & $-2,4666$ & 0,47 \\
\hline$\Delta F C O_{i t}$ & 1,9496 & 0,93 & 1,6941 & 0,05 \\
\hline AbAccit & $-1,6468$ & 0,62 & $-0,5272$ & 0,59 \\
\hline LR Statistic & 5,6752 & 0,12 & 5,6727 & 0,13 \\
\hline McFadden $R^{2}$ & 0,0398 & & 0,0396 & \\
\hline Akaike criterion & 1,3529 & & 1,3528 & \\
\hline Schwarz criterion & 1,4528 & & 1,4530 & \\
\hline$n$ & 107 & & 107 & \\
\hline
\end{tabular}

Modelo empregado para investigar o gerenciamento de resultados na hipótese de evitar variabilidade dos resultados (equação 2):

$E M_{i t}=\alpha+\beta_{1} D T D_{i t}+\beta_{2} A C_{i t}+\beta_{3} \Delta F C O_{i t}$

$E M_{i t}=$ empresa com incentivos para gerenciar resultados, 1 se o resultado líquido da empresa $i$ do ano $t$ dividido pelo seu ativo total no

fim do ano $t$ - 1 for $\geq 0$ e $<0,1$; e 0 se o resultado líquido estiver entre $\geq-0,1$ e $<0$;

$D T D_{i t}=$ diferença líquida entre o montante de despesa e receita tributária diferida da empresa $i$ no ano $t$

$\triangle F C O_{i t}=$ variação do fluxo de caixa das atividades operacionais da empresa $i$ do ano $t$-1 para o ano $t$;

$A C_{i t}=$ acumulações discricionárias da empresa $i$ no ano $t$, calculado pelo modelo Jones Modificado $J M T A C c_{i t}(\underline{\text { equação } 3})$ :

$A C_{i t}=J M T A C C_{i t}==\alpha+\beta_{1}\left(\Delta R_{i t}-\Delta C R_{i t}\right)+\beta_{2} A l_{i t}$

$\Delta R_{i t}=$ variação das receitas líquidas da empresa $i$ do $t$-1 para o ano $t$;

$\Delta C R_{i t}=$ variação da conta duplicatas a receber (clientes) da empresa $i$ do $t-1$ para o ano $t$;

$A l_{i t}=$ saldo da conta ativo imobilizado e ativo diferido da empresa $i$ no ano $t$;

Todas as variáveis ponderadas pelo ativo total no final do ano $t-1$. 
Tabela 6 - Gerenciamento de resultados para evitar variabilidade dos resultados contábeis: modelo Total Accruals KS

\begin{tabular}{|c|c|c|c|c|}
\hline & \multicolumn{2}{|c|}{ PROBIT } & \multicolumn{2}{|c|}{$L O G I T$} \\
\hline & COEFFICIENT & P-VALUE & COEFFICIENT & P-VALUE \\
\hline Interceptor & 0,0137 & 0,95 & 0,0258 & 0,94 \\
\hline$D_{i t}$ & 13,9547 & 0,28 & 22,6265 & 0,29 \\
\hline $\mathrm{FCO}_{i t}$ & 5,5563 & 0,03 & 8,9697 & 0,04 \\
\hline KSTacc $_{i t}$ & 8,0623 & 0,05 & 12,9021 & 0,06 \\
\hline LR Statistic & 8,9471 & 0,03 & 8,7867 & 0,03 \\
\hline McFadden $R^{2}$ & 0,1226 & & 0,1204 & \\
\hline Akaike criterion & 1,3595 & & 1,3625 & \\
\hline Schwarz criterion & 1,5082 & & 1,5112 & \\
\hline$n$ & 107 & & 107 & \\
\hline
\end{tabular}

Modelo empregado para investigar o gerenciamento de resultados na hipótese de evitar variabilidade dos resultados (equação 2):

$E M_{i t}=\alpha+\beta_{1} D T D_{i t}+\beta_{2} A C_{i t}+\beta_{3} \Delta F C O_{i t}$

$E M_{i t}=$ empresa com incentivos para gerenciar resultados, 1 se o resultado líquido da empresa $i$ do ano $t$ dividido pelo seu ativo total no fim do ano $t-1$ for $\geq 0$ e $<0,1$; e 0 se o resultado líquido estiver entre $\geq-0,1$ e $<0$;

$D T D_{i t}=$ diferença líquida entre o montante de despesa e receita tributária diferida da empresa $i$ no ano $t$;

$\triangle F C O_{i t}=$ variação do fluxo de caixa das atividades operacionais da empresa $i$ do ano $t$-1 para o ano $t$;

$A C_{i t}=$ acumulações discricionárias da empresa $i$ no ano $t$, utilizando o total accruals no ano $t$ calculado pelo modelo Jones Modificado

$K S T A C c_{i t}$ (equação 4) : $A C_{i t}=K S T A C C_{i t}==\phi_{0}+\phi_{1}\left(\delta_{1} R_{i t}\right)+\phi_{2}\left(\delta_{2} D_{i t}\right)+\phi_{3}\left(\delta_{3} A l_{i t}\right)$

$K S T A C C_{i t}=$ total accruals da empresa $i$ no ano $t$ através do modelo $\mathrm{KS}$;

$R_{i t}=$ montante das receitas líquidas da empresa $i$ no ano $t$;

$D_{i t}=$ montante dos custos e despesas operacionais da empresa $i$ no ano $t$, excluídas as despesas com depreciação e amortização;

$A I_{i t}=$ saldo da conta ativo imobilizado e ativo diferido da empresa $i$ no ano $t$

$\Delta C G L_{i t}=$ variação do capital de giro líquido da empresa $i$ no final do ano $t$-1 para o ano $t$, excluindo-se as disponibilidades e financia-

mento de curto prazo;

$C R_{i t}=$ montante da conta duplicatas a receber (clientes) da empresa $i$ do ano $t-1$ para o ano $t$;

Depr $_{i t}=$ montante das despesas com depreciação e amortização da empresa $i$ do ano $t$;

$\delta_{1}=C R_{i, t-1} / R_{i, t-1}$;

$\delta_{2}=\left(\Delta C G L_{i t}-C R_{i t}\right) / D_{i, t-1}$;

$\delta_{3}=\operatorname{Depr}_{i, t-1} / A l_{i, t-1}$.

Todas as variáveis ponderadas pelo ativo total no final do ano $t-1$.

\section{REFERÊNCIAS}

BARTOV, E.; GIVOLY, D.; HAYN, C. The rewards to meeting or beating earnings expectations. Journal of Accounting and Economics, v. 33, n. 2, p. 173-204, 2002.

BARTOV, E.; MOHANRAM, P. Private information, earnings manipulations, and executive stock-options exercises. The Accounting Review, v. 79 , n. 4, p. $88-920,2004$

BEUREN, I. M. (Org.). Como elaborar trabalhos monográficos em contabilidade: teoria e prática. São Paulo: Atlas, 2003.

BURGSTAHLER, D.; DICHEV, I. Earnings management to avoid earnings decrease and losses. Journal of Accounting and Economics, v. 24, n. 1, p. 99-126, 1997.
DECHOW, P. M. Accounting earnings and cash flows as measures of firm performance: the role of accounting accruals. Journal of Accounting and Economic, v. 18, n. 1, p. 3-42, 1994.

DECHOW, P. M.; SLOAN, R.G.; SWEENEY, A. P. Detecting earnings management. The Accounting Review, v. 70, n. 2, p. 193-225, 1995.

FUJI, A. H. Gerenciamento dos resultados contábeis no âmbito das instituições financeiras atuantes no Brasil. 2004. Dissertação (Mestrado em Contabilidade), FEA-USP, São Paulo, 2004.

GORDON, E.; JOOS, P. R. Unrecognized deferred taxes: evidence from the UK. The Accounting Review, v. 79, n. 1, p. 97-124, 2004.

GUJARATI, D. N. Econometria básica. São Paulo: Pearson, 2000. 
HEALY, P.; WAHLEN, J. M. A review of the earnings management literature and its implications for standard setting. Accounting Horizons, v. 13, n. 4, p. 365-383, 1999.

JONES, J. Earnings management during import relief investigations. Journal of Accounting Research, v. 29, n. 2, p. 193-228, 1991.

KANG, S. H.; SIVARAMAKRISHNAN, K. Issues in testing earnings management: an instrumental variable approach. Journal of Accounting Research, v. 33, n. 2, p. 353-367, 1995.

KRULL, L. Discussion of decomposing changes in deferred tax assets and liabilities to isolate earnings management activities. The Journal of American Taxation Association, v. 26, supplement, p. 43-66, 2004.

MARTINEZ, A. L. Gerenciamento dos resultados contábeis: estudo empírico das companhias abertas brasileiras. 2001. Tese (Doutorado em Contabilidade), FEA-USP, São Paulo, 2001.

MARTINS, E. Contabilidade versus fluxo de caixa. Caderno de Estudos da Fipecafi, v. 11, n. 20, p. 1-10, 1999.

MCKEE, T. E. Earnings Management: An Executive Perspective. Ohio: Thomson, 2005.

MILLER, G.; SKINNER, D. Determinants of the valuation allowance for deferred tax assets under SFAS N. 109. The Accounting Review, v. 73, n. 2, p. 105-134, 1998.
PHILLIPS, J.; PINCUS, M.; REGO, S. O. Earnings management: new evidence based on deferred tax expense. The Accounting Review, v. 78, n. 2 , p. 491-521, 2003.

PHILLIPS, J. et al. Decomposing changes in deferred tax assets and liabilities to isolate earnings management activities. The Journal of American Taxation Association, v. 26, supplement, p. 43-66, 2004.

QUANTITATIVE MICRO SOFTWARE (QMS). EViews 3 User's Guide. 2. ed. Irvine: QMS, 1998

ROOSENBOOM, P.; GOOT, T. V. D.; MERTENS, G. Earnings management and initial public offerings: evidence from the Netherlands. The International Journal of Accounting, v. 38, n. 3, p. 243-266, 2003.

SCHIPPER, K. Commentary on earnings management. Accounting Horizons, v. 3, n. 4, p. 91-102, 1989

STOLOWY, H.; BRETON, G. Accounts manipulation: a literature review and proposed conceptual framework. Review of Accounting \& Finance, v. 3, n. 1, p. 5-66, 2004.

TEOH, S. H.; WELCH, I.; WONG, T. J. Earnings management and the long-run market performance of initial public offerings. Journal of Finance, v. 53, n. 6, p. 1935-74, 1998.

TUKAMOTO, Y. S. Contribuição ao estudo do "gerenciamento" de resultados: uma comparação entre as companhias abertas brasileiras emissoras de ADRs. Dissertação (Mestrado em Contabilidade), FEA-USP, São Paulo, 2004.

WATTS, R. L.; ZIMMERMAN. J. L. Positive Accounting Theory. New Jersey: Prentice-Hall, Inc., 1986.

Artigo recebido em 02.11.2005. Aprovado em 30.05.2006.

\section{Edílson Paulo}

Professor da Universidade Presbiteriana Mackenzie. Doutorando em Controladoria e Contabilidade na FEA-USP. Interesses de pesquisa nas áreas de contabilidade para usuários externos e métodos quantitativos.

E-mail: e.paulo@uol.com.br

Endereço: Rua Marechal Deodoro, 483, ap. 82, Santa Paula, São Caetano do Sul - SP, 09541-300.

\section{Eliseu Martins}

Professor Livre-Docente da FEA-USP. Doutor em Controladoria e Contabilidade pela FEA-USP.

Interesses de pesquisa nas áreas de contabilidade para usuários externos.

E-mail: emartins@usp.br

Endereço: Av. Professor Luciano Gualberto, 908, FEA prédio III, Cidade Universitária, São Paulo - SP, 05508-900.

\section{Luiz João Corrar}

Professor da FEA-USP. Doutor em Controladoria e Contabilidade pela FEA-USP.

Interesses de pesquisa nas áreas de métodos quantitativos, finanças e atuária.

E-mail: ljcorrar@usp.br

Endereço: Av. Professor Luciano Gualberto, 908, FEA prédio III, Cidade Universitária, São Paulo - SP, 05508-900. 